\title{
Las prácticas evaluativas como proceso holístico en y con el otro ${ }^{1}$
}

\section{Assessment Practices as a Holistic Process}

\author{
Carlos Federico Ayala Zuluaga ${ }^{2}$ \\ Jhon Fredy Orrego Noreña ${ }^{3}$ \\ José Enver Ayala Zuluaga ${ }^{4}$
}

\section{Resumen}

Este documento hace parte de dos investigaciones llevadas a cabo en estudios del programa Maestría en Educación, a partir de las cuales se abordaron los temas de las prácticas evaluativas y la alteridad en la formación de maestros. Alrededor de estos asuntos se reflexiona sobre las relaciones de alteridad estudiante-maestros y la influencia sobre los procesos formativos y los de evaluación que se manifiestan en la práctica. El material que se utilizó fue la entrevista estructurada a profundidad. Enfoque histórico hermenéutico, mediante el método cuasi-etnográfico. Como resultado de este encuentro, presentamos una propuesta de estudio, elaboración y ejecución entre las diferentes prácticas evaluativas en correspondencia con y en el otro, dentro del contexto de la formación profesional de profesores, en el área de la educación física, la recreación y el deporte. Por lo tanto, concluimos, a partir de la relación entre ambas tesis y de dichos elementos (alteridad, prácticas evaluativas y formación de maestros), cómo las concepciones que se tienen de educación y de estudiante generan un tipo de evaluación en correspondencia con estas.

\section{Palabras clave}

Formación, alteridad, evaluación, prácticas evaluativas, proceso integral.

\section{Abstract}

This document is part of two research projects carried out in studies in Master's in Education which deals with the assessment practices and otherness in teacher education. Surrounding these topics, this article reflects on the issue of otherness in student-teacher relationships and their influence on teaching processes and assessment practice. The necessary information was gathered by means of a structured and in depth interview using a hermeneutical approach through the quasi-ethnographic method. As a result of this meeting, a study proposal for study, development and implementation among the different assessment practices in keeping with the other, within the context of teacher training in the area of physical education, recreation and sport was presented. Therefore, we conclude, based on both the thesis and the mentioned elements (otherness, evaluative practices and teacher training), that the conceptions of education and of the student generate a particular type of assessment.

Keywords

Training, otherness, assessment, assessment practices, integral process.

Artículo recibido el 31 de octubre de 2013 y aprobado el 29 de agosto de 2014

1 Investigación "Sentido de las prácticas evaluativas en el programa de Educación Física, Recreación y Deporte de la Universidad de Caldas". Período 2008-2010. Entidad Universidad de Caldas. Investigación “La alteridad en la formación del licenciado en Educación Física de la Universidad de Caldas", 2007-2009. Entidad Universidad de Caldas.

2 Universidad de Caldas, Manizales, Colombia. Correo electrónico: federico.ayala@ucaldas.edu.co

3 Universidad de los Llanos, Villavicencio, Colombia.

4 Universidad del Quindío, Armenia, Colombia. 


\section{Un punto de partida}

Asistimos a un crecimiento constante en la producción de conocimiento en muchos campos, asimismo ocurre en la formación de maestros, las prácticas evaluativas y su relación con la alteridad; reflexiones que se abordan desde diversas perspectivas, intenciones y modelos, siempre con la expectativa y pretexto de mejorar la calidad de la educación. Es importante decir, que si bien no son múltiples los abordajes investigativos y teóricos que asumen la relación entre alteridad y evaluación, son más abundantes su tratamiento de manera separada, las reflexiones de este trabajo intentan desarrollar unas aproximaciones, en cuanto se considera que la evaluación desde y con el otro no puede ser asumida como un hecho mediático y de desarrollo simple, esta necesita profesionales con una alta capacidad de reflexividad y formación en el asunto planteado, por ello se asume que debe ser una preocupación y construcción desde las instituciones encargadas de la formación del maestro.

Una inquietud permanente es el lugar del sujetoeducador y del sujeto-estudiante en dichas reflexiones; ante esto surgen interrogantes como ¿qué se debe evaluar? ¿El aprendizaje adquirido, las estrategias utilizadas, la pertinencia de los conocimientos, los procesos, etc.?, elementos estos que se realizan en torno del sujeto y el papel que cumple en las instituciones educativas. Junto con estas preguntas, se hace necesario considerar el cómo los actos educativos involucran diferentes dimensiones del ser humano en lo físico y lo cognitivo en una unidad psicobiológica: el deseo, las emociones, las apreciaciones, las circunstancias, las percepciones y la necesidad de relaciones comunicativas e interactivas con otros y hacia la auto-realización, como fin último de la vida humana y del hombre en su indisolubilidad entre cuerpo, alma y espíritu (Díaz A., Barrón y Díaz F., 2008; Ospina, 2007); lo que permite que se dé esa relación con y en el otro, pues la educación admite y fomenta el diálogo, la comunicación y el compromiso con mi mundo y el del otro (Cecchini, 1996).

En los actos educativos, pedagógicos y didácticos de la evaluación, hoy en día se debe procurar por la apertura, la participación, el pluralismo y la independencia en la aplicación de estos (Díaz A. et al, 2008), por la calidad, la democracia, la autocrítica, los procesos y la responsabilidad con principios y valores, que construyan procesos de indagación sobre el valor de la formación y de la educación, de su importancia, de sus exigencias y sus significados (Santos, 1999).

Lo anterior lleva a considerar al sujeto de la educación en una dinámica de vida que contribuye al proceso educativo y formativo, con nuevos estudios y enfoques en lo epistémico, psicológico y pedagógico, para ver, interpretar y ubicarse frente al conocimiento (Álvarez, 2003) con unos elementos claves en las capacidades superiores de inteligencia y voluntad, de la ética y la moral (Ospina, 2007). Por ello, y con base en las dos investigaciones de las que se desprende este artículo (ver nota al pie 1), se considera importante definir el contexto, la epistemología y la concepción de lo que son la formación de maestros, las prácticas evaluativas en los programas de formación docente (para este caso, en el área de la educación física), y las concepciones de sujeto-otro ${ }^{5}$ que se evidencian entre una u otra práctica evaluativa.

\section{Algunos acercamientos a la formación del maestro}

La formación del maestro ha tenido innumerables vertientes, pero en los últimos tiempos se desarrolla desde el denominado "debate pedagógico". ${ }^{6}$ La historia de este proceso inicia con las diferentes concepciones; una de las cuales se concentra en cómo

5 En el marco de este trabajo, se asume como otro, a cada sujeto que converge en el aula de formación, dando cabida a la novedad, al descubrimiento y a lo excepcionalmente otro del otro que altera al sujeto propio. Esto fundamentado desde la teoría de Emmanuel Levinas. Ver de este autor Totalidad e infinito (1961), Humanismo del otro hombre (1974), entre otros.

6 Según Fernández (2007) en Colombia el debate pedagógico tiene su organización a partir de 1982, en dicha época, los académicos de las universidades se encargaron de darle mayor rigor científico; si bien este proceso fue sistematizado, los sindicatos y otras organizaciones gremiales afirman que el tema nace con el sindicalismo magisterial que tiene sus orígenes en la década de los años treinta del siglo XX, para ampliar ver revistas Educación y Cultura, colección año 2007 
es "visto" el maestro en la comunidad en general. Se le concibe como un personaje ligado a la escuela; allí la cultura que genera cada sociedad lo ve como un profesional que debe tener una importancia vital en su rol; pero según el contexto cultural, el maestro es visto o no como dinamizador de dicha cultura.

Las concepciones de maestros están matizadas preferencialmente con la forma como se realiza el acto educativo y según el logro o aporte que brinda a las diferentes sociedades. Con lo anterior, y al revisar las diversas corrientes pedagógicas, se encuentran posiciones sobre cómo es considerado el maestro. Por ejemplo, Meirieu y Develay (1992, p. 38) mencionan que a partir del movimiento de formación francés que se centra en el principio de la libertad, surgen discursos y actividades para que la sociedad conciba de forma positiva su papel e importancia.

En el plano latinoamericano se viene gestando desde la década del setenta un movimiento educativo-pedagógico (Hernández, 2007) que anuncia la importancia de la formación de maestros. Este movimiento concibe a los educadores como actores fundamentales en la transformación del contexto. La educación debe responder por un profesional altamente capacitado, que contribuya al cambio social a través de su quehacer. (Hernández, 2007, p. 15).

Como se devela, estas corrientes educativas de la formación del profesorado tienen implícito el hecho del desarrollo social, en ellas se nota la situación del pensamiento o la asunción del otro como sujeto que debe estar en la formación, si bien se puede decir que es algo implícito, estos postulados no son explícitos en los principios de las mismas y aquí cabe la relación y necesidad de pensar esa formación en el sentido del otro, que lleva a pensar, entonces, si la formación en evaluación para los maestros está considerando la alteridad.

En cuanto a la formación docente en Colombia, su organización se viene construyendo gracias a amplios debates e investigaciones (Zuluaga, 1989, Zuluaga, Echeverri, Quiceno, Sáenz y Álvarez, 2005, Valencia y Portela, 2003). Desde los aspectos legales, el Ministerio de Educación Nacional en el Decreto
2566 de 2003 define las características de la formación de maestros, las cuales se deben mover hacia la calidad, de manera que trasformen la realidad. Al respecto se le concibe así:

Ninguna reforma de la educación puede dar resultados positivos sin la participación activa y cualificada de los educadores. Una educación con calidad mantiene una estrecha relación con un educador de excelente calidad. Por tanto, mejorar las condiciones del maestro, transformar los programas y constituir con él una nueva forma de ser maestro, es el desafío más urgente que afrontan las sociedades en la actualidad, en su tránsito hacia sociedades de conocimiento. (Ministerio de Educación Nacional, MEN, 2003, p. 33)

Se habla entonces de los núcleos de educabilidad, enseñabilidad, la estructura histórica y epistemológica de la pedagogía, las realidades, tendencias sociales y educativas institucionales, nacionales e internacionales; igualmente, se ausculta la estructura más profunda de la teoría y epistemología del tema en cuestión. Los núcleos de fundamentación pedagógica, tal y como se plantean, articulan distintos tipos de conocimientos y modelos alrededor de los temas primordiales; pero también articulan conjuntos de problemas de la realidad y de la experiencia educativa para ser investigados, analizados, comprendidos y resignificados con apoyo en teorías científicas. Por consiguiente, el núcleo del saber formativo corresponde al apoyo básico en la formación de los educadores.

Con lo anterior, se puede decir, entonces, que existen posturas teóricas (Meirieu y Develay, 2003; Zuluaga et al., 2005; Tamayo, 2001; Barbero, 2003) que muestran lo deseable, el deber ser y los logros que se han alcanzado en la educación y en la formación de maestros. Asimismo, que ese deber ser no puede seguir siendo un invitado invisible o solo discursivo en la educación, se hace preciso profundizar en otros aspectos de la formación de maestros, como la transformación de las instituciones en cuanto a la atención y respuestas educativas, a las oportunidades de aprender y la participación curricular, que incluya al otro (Vélez, 2013) y que 
retome la evaluación como dinámica significativa e importante en la educación y en los profesionales que la ejercen.

Con este panorama, es preciso preguntarse por los núcleos de formación pedagógica, por la forma de encarar la disciplina específica que se enseña, por el conocimiento de diversos saberes o por otras emergencias de saberes que puedan darse, aquí las relaciones con alteridad y evaluación son esenciales para buscar procesos de índole académica que den cuenta de las intervenciones que pueden contribuir en la mejora y avance de la sociedad en la cual se hacen las intervenciones, adicional de quiénes y porqué las hacen.

\section{La alteridad: una mirada sobre la formación del otro}

Antes de hacer referencia a la evaluación y sus prácticas, se considera necesario recorrer los intersticios de la alteridad en la formación, a través de los cuales el futuro licenciado construye las vivencias necesarias para su vida profesional. Para Orrego (2009) la formación está directamente relacionada con la adquisición de todos aquellos elementos que construyen y reconstruyen constantemente al hombre, que lo vinculan a una sociedad y una cultura, así como a sus creencias, mitos y formas de ver el mundo, pero que a su vez le permiten ser crítico de dicho espacio, de acuerdo a su modo particular de vivir en él.

Elementos que se construyen y reconstruyen en una relación permanente con el otro, pues es él quien permite que nos identifiquemos como parte de una cultura, que nos reconozcamos como diferentes y únicos, es con el otro que nace la diversidad, el lugar exacto donde emerge la alteridad; pues como lo expresa Levinas (1993): "El otro en cuanto otro no es solamente un alter ego: es aquello que yo no soy. $Y$ no lo es por su carácter, por su fisonomía o su psicología, sino en razón de su alteridad misma” (p. 127).

La alteridad en la formación es, entonces, todo aquello que hace de cada sujeto un ser único e irrepetible, que le permite construir una identidad propia, proyectarse en relación a su contexto; que se juega en los intersticios de la constitución personal, y hace parte fundamental de las experiencias significativas de aprendizaje que se van adquiriendo durante el transcurso de la vida y que se encuentran en diferentes instancias sociales como su familia, sus amigos, la escuela, incluso los medios masivos de comunicación y todas aquellas influencias que le permiten construir su forma única de ver, comprender e interpretar el mundo que le rodea.

Desde la filosofía levinasiana, la alteridad se encuentra más allá de la diferencia entre los sujetos, es la responsabilidad y acogimiento del otro sin esperar nada a cambio, es otro que se impone como total novedad y que "altera" la misma constitución del ser, en ese encuentro, cada quien - ego y alter, uno y otro- se transforman, cambian, acontece en esta relación la formación del sujeto, donde se reafirma la identidad al reconocer la total presencia del otro, distante de ser mi reflejo y/o instrumento de identificación se presenta como apertura.

Se podría asumir la alteridad en un sentido esencial como el descubrimiento que el yo hace del otro, en cuanto que ese otro es un yo que me ve como otro. Para Levinas (citado por Gutiérrez, 2003), “[...] el otro más que constituirse en mi diferencia, identidad deficiente en relación a la mía, es mi excepción, mi primera excepción. El otro es aquello que yo no soy"; o como el mismo lo diría "el otro no es un ser que en relación a mí es de otro modo, sino que el otro es ser de otro modo que ser"; es decir, en tanto que el ser-otro se encuentra a partir de la relación entre sus características de identidad y de diferencia en relación a las propias (el ego), la alteridad se encuentra inmersa más allá de ese ser, es la esencia que lo soporta y que lo lleva a expresarse, identificarse y diferenciarse con los otros.

Al respecto de la alteridad y su relación con la formación, Gadamer (1960, citado por Mèlich, 1983, pp. 98-101) encuentra tres tendencias acerca de las relaciones de alteridad; y que, a su vez, encuentran directa relación con los trayectos de formación expuestos por Ferry (1991), a saber:

\section{a. Instrumentalización del otro y dela formación}

Desde esta mirada, la alteridad y la formación se reducen al proceso más técnico e instrumental (Mèlich, 1983), donde el otro, simplemente, es una herramienta para alcanzar fines propios, no se reconoce la historia del sujeto, no se reconoce su trayecto 
de formación, tan solo entra en juego su capacidad de aprendizaje, de adquirir conocimientos (Ferry, 1991, p. 70) sin ninguna reflexión, tan solo memorización. En el proceso de formación del maestro esto se evidencia cuando se generan transmisiones de conocimiento mas no aprendizajes para la vida, así queda reducida a la instrumentalización del conocimiento y el sujeto que aprende es una simple vasija vacía que requiere ser llenada, tal como lo denunciaba Freire (1987):

[...] el educador, conduce a los educandos a la memorización mecánica del contenido narrado. Más aún, la narración los transforma en "vasijas", en recipientes que deben ser "llenados" por el educador. Cuando más vaya llenando los recipientes con sus "depósitos", tanto mejor educador será. Cuanto más se dejen "llenar" dócilmente, tanto mejor educandos serán. De este modo, la educación se transforma en un acto de depositar en el cual los educandos son los depositarios y el educador quien deposita. (p. 51)

Este vaciamiento de información, se presenta de manera unilateral e impositiva, en el que el profesor que se asume dueño del conocimiento, lo manipula $y$ lo transmite en un sentido vertical, debido a que el estudiante siempre será inferior al profesor, así el conocimiento se convierte, no en un elemento de formación que debe fluir en las aulas, sino en un dispositivo de poder que es utilizado para apaciguar la particularidad del otro - sus pre-saberes-, la exigencia por la novedad en las metodologías y la actualización de los conocimientos (Honoré, 1980). Por tal motivo, queda en evidencia la relación jerárquica, vertical y de poder del educador sobre el educando, en donde el primero se da a conocer como el dueño del conocimiento mientras el segundo es un simple receptor de este.

En este sentido, Bárcena y Mèlich (2000, p. 4) plantean una crítica a la sociedad actual que convierte al sujeto en producto de un proceso de fabricación (escuela), que debe pasar por los estándares de "calidad" para cumplir alguna función definida, olvidando el verdadero sujeto detrás del aprendizaje, la hospitalidad y acogimiento del recién llegado al proceso educativo, pues, mediante procesos de inclusión, los diferentes agentes educativos e institu- cionales en sí mismos deben acoger, aceptar y estar dispuestos a integrar a los estudiantes a partir de sus diferencias y la diversidad humana (Vélez, 2013).

Respecto a esto último, Romero (2004) se refiere a lo que él denomina el discurso técnico de la formación como aquellos saberes que solo requieren ser aprendidos, sin que medie la participación del estudiante, el análisis crítico de los contenidos o la apertura del docente:

El experto, el profesor de Universidad, es el que posee el conocimiento, el cual se presenta como "dado por sentado" y el estudiante (futuro profesor) es un receptor pasivo del conocimiento con poca participación en el proceso de formación. Se enfatiza sobre el academicismo universitario, esto supone que la adquisición de conocimientos de las distintas asignaturas que integraban el currículo formativo deben proporcionar las competencias necesarias para la actividad profesional prevista. Así, a través de los conocimientos teóricos, que se suponía que se debían adquirir a su formación inicial, se satisfacían las necesidades de la práctica.

(Romero, 2004, p. 9)

\section{b. La formación como proceso y el otro como análogo}

Para este caso, se empieza a reconocer el otro como sujeto, diferente, pero aun así su existencia es concedida a la propia conciencia, es decir, el otro solo se presenta en la conciencia, fuera de la cual no podría existir. En este sentido, surge en el afán por superar las percepciones que dejan al ser solo en el mundo, en cuanto ser rodeado de objetos, surgen posturas colectivistas, lo que vendría a ser el otro extremo, pues el ser individual solo es un eslabón en la colectividad (Gevaert, 1984, p. 40).

Este proceso, inicialmente, está mediado por la interlocución, en la que el compartir la aceptación del otro, la apertura a la diversidad es más que simples designaciones del aspecto socioafectivo, en un contexto educativo se transforman en posibilidad de formación, en mediación entre docentes y estudiantes, y en una herramienta seductora para los aprendizajes; "[...] consiste en saber escuchar y mirar el rostro del otro, de otro que en medio de sus constantes fugas y escapatoria logra silenciar el 
discurso del docente y lo obliga a mirarlo como un rostro, con voz y saber" (Zambrano, 2000, p. 100).

Es dar cabida a lo que el otro puede ofrecer, es permitirse, como docente, aprender de él y hacer de cada escenario y momento educativo una experiencia nueva, atrayente y enriquecedora. La interlocución como mediación pedagógica traspasa los espacios de clase directamente y se expande hacia otros escenarios de encuentro y relación más sociales, donde la confianza y la cercanía entre docentes y estudiantes, que se ha iniciado en clase, es aprovechada para nutrir y profundizar en los conocimientos, pero también para fortalecer las relaciones entre los sujetos y hacer más ameno no solo el aprendizaje sino el mismo deseo de asistir a clases.

Lo anterior, es evidencia de que siempre requerimos a otros como referencia para aprender y a quienes enseñar, para compartir y para madurar; así mismo, la educación y la formación son procesos exclusivamente humanos y sociales, donde el otro juega un papel primordial, ya que nos permite identificarnos como parte de un grupo, con una meta común; en un nivel superior, los compañeros se convierten en un gran apoyo académico, debido a que es con ellos que se realizan los trabajos, se comparten las responsabilidades, y además quienes nos llaman la atención cuando algo puede estar saliendo mal, el otro desde su particularidad nos ayuda a construir la nuestra, a reconocer nuestras fortalezas y debilidades: "No aprendemos nada con quien nos dice: 'Haz como yo'. Nuestros únicos maestros son aquellos que nos dicen 'hazlo conmigo', y que en vez de proponernos gestos para reproducir, saben emitir signos desplegables en lo heterogéneo" (Deleuze, citado por Bárcena y Mèlich, 2000, p. 60).

\section{c. El otro como apertura}

Desde este enfoque, el otro se presenta como emergencia, como posibilidad de construcción y reconstrucción del ser y del conocimiento; pues, ese otro ya no es manipulable, ya no se asume como igual al sujeto-ego, es radicalmente novedad, se asume con responsabilidad, acogida y hospitalidad al llegar como nuevo a un mundo compartido por unos y otros.
Así, la formación más allá del transmisionismo, la memorización o los procesos que procuran los aprendizajes, es el análisis crítico (Ferry, 1991, p. 77-79) y permanente del conocimiento, su transformación, su posibilidad de cambio y lo que históricamente ha producido la ruptura de paradigmas y la generación de otros.

En la práctica formativa el reconocimiento del otro es una estrategia metodológica que da apertura a la fluidez de experiencias, de expectativas, a construir un escenario educativo desde la diferencia y la posibilidad de lo diverso, pero, además, al tener en cuenta al otro-estudiante, es buscar las maneras propicias de llegarles, de acercarles al conocimiento, la formación del maestro no se debe quedar en una sola forma de transmitir, en una sola forma de participación o de socializar los saberes requeridos, gracias a que "[...] ningún estudiante aprende de la misma manera, por lo tanto, la acción pedagógica y didáctica del docente debe apoyarse en las diferencias intelectuales del alumno" (Zambrano, 2000, p. 58).

Esta es la apuesta por el reconocimiento del otro como apertura, según lo plantea Gadamer (1960, citado por Mèlich, 1983) y desde donde Levinas construye toda su apuesta por darle el lugar al otro en el mundo de la vida, más allá de cualquier existencia psíquica en el yo o como un análogon que solo invita al mimetismo pero no al reconocimiento esencial del otro.

Pensar la alteridad implica, entonces, estar dispuesto a dejarse atacar por el otro, por su subjetividad, su forma de ver el mundo, vivir en él, de percibirlo e interpretarlo, formas que son diferentes a las propias, y en ese sentido es un dejarse "alterar" por el otro; porque eso es la alteridad, es lo otro del otro que altera al ser.

El análisis que permite la transformación del conocimiento, no se limita al aula como único escenario de formación, sino que la trasciende hacia otros espacios de encuentro, en donde las relaciones y los saberes se fortalezcan; esto quiere decir, de un lado contextualizar los conocimientos y, de otro, implica, también, convertir en conocimiento 
las experiencias. En este proceso de contextualización y "textualización" es importante encontrar otros espacios en donde los docentes y los estudiantes pueden profundizar sobre el conocimiento, pero sin los límites que marcan el tiempo de clase, las paredes del aula y los planes de trabajo de las asignaturas. Allí el saber fluye más libremente, se pregunta sin presiones, sin miedo a las críticas, allí todo es constructivo.

Lo anterior, permite ver la formación del estudiante como un tránsito marcado por múltiples tensiones (políticas, económicas, sociales, culturales, éticas, e incluso de conocimiento, entre muchas otras) que se encuentran reflejadas en los procesos desarrollados en el aula, en los maestros que tienen la responsabilidad de instruir o construir el conocimiento y en las relaciones que se encuentran allí; tensiones, ligadas unas con otras y que al final del camino, determinan también las prácticas evaluativas.

\section{La evaluación como proceso holístico ${ }^{7}$}

En la teoría y la práctica, se ha defendido que la educación es importante para los procesos que contribuyen en la formación holística del ser humano, en estos hay aspectos que intervienen directa o indirectamente en su calidad, entre los cuales tenemos las prácticas evaluativas: "la educación es una práctica social, y la evaluación, uno de sus principales componentes y compromisos" (Hernández y Moreno, 2007, p. 215); asimismo, desde diferentes conceptualizaciones y concepciones se esgrime la evaluación como procesos para recoger información, emitir juicios que tengan valor cualitativo o cuantitativo (Blázquez, 2003), determinar el grado de logros alcanzados (Ahumada, 2001), verificar desempeños y posibilidades del estudiante de trasformar programas educativos, acciones pedagógi-

7 En este documento se asume el concepto de holístico, a partir de entender y comprender el fenómeno de la evaluación en diferentes componentes e incluso propiedades originales de esta, que permita hacer conexión, incorporación e interiorización de los procesos educativos en relación individual y conjunta con, desde y para el otro, en el contexto de la formación de profesores, especialmente en la educación física. cas, en construir conocimiento y reflexionar sobre el proceso evaluativo (Guío, 2011).

Por eso, mediante diferentes funciones, tales como el diálogo para el debate, la comprensión desde la reflexión y el mejoramiento como producto del cambio, se permite que el juicio de valor sea en la evaluación un producto compartido, directa o indirectamente, de la plática, la discusión y las reflexiones (Santos, 1998, 1999), lo cual admite y fomenta que la evaluación sea dialógica, formativa, compartida, comprensiva y cualitativa, dando cuenta de lo holístico, precisando de diferentes procesos, herramientas y subsidios evaluativos.

Los procesos educativos, entonces, deben involucrar mucho más que al docente, también a los estudiantes, a los administrativos, a los padres de familia y a la comunidad en general, en actos de participación activa, de diálogo, de motivación y de orientación (Gonzáles, 2003) y, además, buscar que estos contribuyan a los procesos de formación de lo ético, lo social, lo cultural, lo estético y lo educativo, entre otros aspectos (Saavedra, 2013), pues los procesos evaluativos holísticos buscan perfeccionar al profesional de la educación en la independencia, en los juicios, en la interrogación y en el entendimiento de lo que sucede con el mismo proceso en las instituciones y sistemas (Santos, 1999).

Algunas de las concepciones que se hallan en torno a la evaluación y que responden a los intereses actuales de la formación de profesores de manera holística, se sintetizan en los planteamientos de Cerda (2003), quien invita a utilizar la evaluación para juzgar e inferir sobre la información recogida y mostrar la realidad del proceso, ya sea para afirmar o negar cantidades y cualidades del objeto o sujeto evaluado. Villada (2007) también plantea que las prácticas de evaluación deben ser un conjunto sistémico de estrategias, procedimientos, fundamentos y categorías que permitan la examinación, que conduzca a emitir juicios y conceptos valorativos; igualmente, para valorar sus características y condiciones en función de unos criterios y puntos de referencia, con el fin último de emitir o producir un juicio relevante para el proceso y los sujetos inseri- 
dos en este (Sacristán y Pérez, 1995); en definitiva, un proceso evaluativo de tipo holístico debe permitir o posibilitar que los actores de este participen de

\section{[...] forma activa de la valoración de su propio} proceso de aprendizaje y que los juicios y valoraciones generen reflexiones y actitudes que produzcan la comprensión, la reflexión y la autovaloración de los aprendizajes alcanzados para la consolidación de un mejor ser humano y en perspectiva de procesos educativos de calidad, para ello deben ser objeto de evaluación todos los elementos que inciden de manera relevante en el proceso educativo. (Guío, 2011, p. 72)

Por lo tanto, cuando se habla de la evaluación como proceso holístico, se entiende esta con particularidades que la definen, tales como la conceptualización de objetivos (pretensiones) puntuales, su funcionalidad, los procesos sistemáticos de integración y de inserción por parte de los actores de este. Su continuidad al permitir revelar y edificar las carencias en el proceso, en lo cognoscitivo, lo cognitivo y lo comportamental (Ayala y Loaiza, 2012). Esto admite visualizar o entender que en ella hay participación de varios actores educativos, los cuales parten de diferentes fenómenos que inciden en sus intereses, deseos, expectativas y conocimientos; por lo que la retroalimentación, la argumentación crítica y reflexiva, y las actividades dialógicas, fomentan entre los estudiantes nuevos horizontes y perspectivas para mirar al otro, para que juntos planteen dificultades, las resuelvan y las orienten adecuadamente en su proceso de formación docente (Saavedra, 2013).

La evaluación como proceso holístico se enmarca esencialmente en una comprensión cualitativa de este, pues la complejidad y multifactorialidad de los aspectos y fenómenos que la envuelven, solicitan que sus funciones sean de tipo diagnóstico, adaptativo, controlador e informativo (Chahuán-Jiménez, 2009) en lo pedagógico y didáctico de la enseñanza y el aprendizaje (Hernández y Moreno, 2007).

Aunque a partir de las perspectivas de formación, alteridad y procesos evaluativos, es necesario hacer relaciones entre estas para el mejoramiento de la calidad de la educación, dando respuestas a las necesidades educativas del y con el otro en su multidimensionalidad humana (Condemarín y Medina, 2000), permitiendo prácticas evaluativas holísticas, comprendiendo las complejidades pedagógicas y las interrelaciones de los procesos que se exhiben entre estudiantes y profesores en la enseñanza y el aprendizaje, la investigación, la docencia y la extensión (Vásquez-Rizo y Gabalán-Coello, 2012).

\section{Prácticas evaluativas que dan cuenta del otro}

\section{a. Las prácticas evaluativas inmersas en el proceso de formación profesional en edu- cación física}

En diferentes reformas educativas que se proponen y desarrollan en las naciones, generalmente está inmerso el tema de la evaluación educativa, donde se plantean esquemas, estrategias y condiciones con el objetivo principal de mejorar la calidad en la educación, considerando que los actos educativos puedan generar incorporaciones en el rol docente, las relaciones recíprocas, profundización en la adquisición del conocimiento, entendimiento de los procesos curriculares, el desarrollo de una educación centrada en los aprendizajes y la calidad de estos (Chahuán-Jiménez, 2009), y en la didáctica y metodologías de enseñanza y aprendizaje.

Desde esta perspectiva es importante incluir en los procesos de formación de profesores aspectos evaluativos, de manera que contribuyan al mejoramiento, al desarrollo y al perfeccionamiento del rendimiento y del desempeño académico en la participación recíproca, la organización conjunta del proceso, la autonomía organizativa, la auto y la co-reflexión participativa y comprensiva de los actos educativos (Ayala y Loaiza, 2012), ya que así se vislumbra el aprendizaje producido mediante una participación imprescindible de los estudiantes en el proceso de evaluación, pues esta se convierte en una base de la discusión y del diálogo sobre lo que se propone, se cuestiona, las condiciones y los resultados obtenidos de la misma (Santos, 1998), y que estos además contribuyan a la formación académica y profesional de los educandos. 
En dicha formación la actitud reflexiva y critica, las técnicas de operacionalización de los procesos, la responsabilidad personal y colectiva, la apropiación de conexiones e innovaciones con las políticas sociales, culturales, económicas, administrativas, de enseñanza y aprendizaje, debe permitir "nuevos referentes teóricos, nuevas concepciones curriculares, nuevas sugerencias metodológicas, en suma un nuevo rol docente" (Paukner-Nogués, SanhuezaHenríquez y San Martin-Ramírez, 2012, p. 361), que sepa intervenir y certificar la eficacia y eficiencia de estos y que propenda por el crecimiento en la formación docente, desde el entorno, las interrelaciones, las conductas y los comportamientos (Vásquez-Rizo y Gabalán-Coello, 2012).

\section{b. Evidencia subjetiva de un proceso de evaluación holística que integre al otro}

Como ya se planteó anteriormente, se propone que las prácticas evaluativas desde la perspectiva de lo holístico y la alteridad giren en torno a las esferas del ser humano, esencialmente en la formación del carácter y la personalidad, en aspectos como el lenguaje, el trabajo, la socialización, las experiencias, el mundo de la vida, las tradiciones, costumbres y normas (Dewey, citado por Mejía, Arias y Pórtela, 2007), de tal modo que el docente y el estudiante puedan comunicarse con su alteridad y con la del otro, en un proceso de formación recíproca, comprometidos con su formación y transformación (Fichte, 1977).

Los procesos poscontemporáneos de valoración de los aprendizajes, por la diversidad de aprendizajes, inteligencias, perspectivas y miradas que se tienen al respecto, se deben asumir de manera holística (Ayala y Loaiza, 2012), de forma que se involucren profesores, estudiantes, directivos, padres de familia y la comunidad (Hernández y Moreno, 2007), en la cual lo que se plantea y lo que se hace, lo que se piensa, se propone y se realice, lleve a un sistema de interacción de los procesos educativos (Cerda, 2003).

Así, las prácticas evaluativas holísticas que integran la alteridad tendrán su punto de encuentro en la formación y la educación, en el momento y espacio en que florezca el convivir respetuosamente con el otro, donde las decisiones coexistan y sean aceptadas desde la perspectiva del que las plantea y donde su individualidad, confianza e identidad estén respetadas por el otro, sin presentarse el temor de que desaparezca el otro en la relación (Maturana, 1998). También se asume que el diálogo recíproco y constante, la participación reflexiva en el porqué de las situaciones, la proyección con el otro a partir de sus dimensiones humanas, la confrontación, las ideas, los conceptos, la presentación de propuestas y la individualización de sus acciones (Ayala y Loaiza, 2012), permitirá desenvolver y desarrollar un proceso evaluativo que involucre la mirada del estudiante como actor fundamental del procesos educativo y evaluativo.

\section{c. Prácticas evaluativas y la alteridad a partir de la medición y el control}

Independientemente de que las valoraciones de los aprendizajes sean mediadas por la medición y el control, desde una perspectiva holística con el otro, se pretende orientar para el fomento y servicio de los valores, la disciplina, el encuentro mediado, la comprobación de los aprendizajes y la enseñanza, el uso de signos y símbolos cuantitativos y cualitativos, la valoración de su presencialidad y asistencia, el mejoramiento de su nivel inicial, la capacidad de elaborar, sustentar y dominar temáticas, y de ser propositivos (Ayala y Souza, 2012), por eso, a partir de las practicas evaluativas como medición y control, desde esta perspectiva, lo que se debe pretender es que la evaluación sea " un instrumento de diagnóstico, aprendizaje y de comprensión encaminada a la mejora. [...] Quien tiene capacidad de evaluar establece los criterios, los aplica de forma e interpreta y atribuye causas y decide cuales han de ser los caminos de cambio" (Santos, 1998, pp. 14-16).

Procesos educativos que transformen a los actores, a partir del control de sus errores y aciertos, que sean partícipes de las decisiones y conscientes de las realidades, las limitaciones y los alcances, como signo de equidad entre estos, en el mejoramiento de la enseñanza y el aprendizaje (Ayala y Souza, 2012), donde la alteridad en el otro genere encuentros intersubjetivos en la percepción de los 
aprendizajes y las maneras más adecuadas de valorar lo verdaderamente aprendido por el estudiante. Maestro y estudiante se reconocen como elementos diferentes pero que se integran en una dinámica de reconocimiento y transformación para cumplir el fin de la educación, el cual es la formación humana.

\section{d. La evaluación dimensional con y en el otro}

Este tipo de prácticas evaluativas se encuadran dentro de la objetividad, subjetividad y la intersubjetividad de las personas, permitiendo trasformaciones en el proceso de enseñanza-aprendizaje, donde el análisis, la comprensión y el cambio están directamente relacionados con los sujetos, fomentando la democracia, la participación y la crítica responsable, valorando el ego y el alter, tanto individual como colectivo; situación que se evidencia, por lo que "[...] al interior de la evaluación deben ocurrir cosas [...], en otras palabras, en el proceso educativo. $\mathrm{Al}$ interior de la evaluación se encuentra el ser humano como un ser subjetivo, con características personales, individuales como un ser irrepetible" (Villada, 2002, p. 18), situación de la cual da cuenta la alteridad en la perspectiva dimensional de la evaluación.

Con base en lo anterior, la autoevaluación en la evaluación dimensional contribuye al proceso de aprender a evaluar en relación con y en el otro, ya que en esta el estudiante participa de su propia evaluación entendiendo que corregirse, avaluarse, analizarse y criticarse, es una manera de reflexionar activamente en la formación docente (Ayala y Loaiza, 2012), pues la autoevaluación:

[...] es un proceso claramente institucionalizado donde no solo se autoevalúen los conocimientos adquiridos, sino también actitudes, estrategias, maneras de ser y de actuar. Se trata de establecer una reflexión completa sobre todos los efectos de la acción educativa. Para hacerlo posible, resulta imprescindible definir una pautas, unos criterios, un enfoque y naturalmente unos indicadores que den cuenta del proceso que se propone. (Ríos, 2004, p. 38)

La coevaluación fomenta la participación valorativa, activa y recíproca con el otro, donde se asume el rol de docente (Ayala y Loaiza, 2012), mediante "un intercambio de juicios valorativos entre varios alumnos, derivados de la aplicación de instrumentos o sin ellos y con base en parámetros previamente definidos" (Camacho, 2003, p. 189). La responsabilidad es el objetivo central de la heteroevaluación, donde la experiencia, los saberes, los conocimientos permiten valorar los desempeños del otro, a partir de lo subjetivo, lo objetivo e intersubjetivo de cada sujeto, ya que esta "corresponde a la estructura y dinámica propia de las otras personas como seres diferentes, pero cercanos y no lejanos" (Villada, 2008, p. 45).

Estas prácticas evaluativas dimensionales tienen su potencial en los procesos que involucran los consensos, las oportunidades, los seguimientos, la participación de manera conjunta, el debate, la confrontación y cooperación con y en el otro:

La valoración de los aprendizajes de los sujetos por parte de otros requiere el compromiso de juzgar desde las comparaciones y los referentes de valor con criterios cargados de subjetividades, en las cuales se busca describir situaciones educativas con intenciones de favorecer las evaluaciones que permitan aprender mejor; por eso la participación de otros en el proceso evaluativo es innovador y motivante para el estudiante en su proceso de formación académica y profesional, la cual siendo realizada, orientada y organizada por el docente y ayudada por los mismos estudiantes, permitirá y desarrollará la responsabilidad en el alumno hacia una participación total en el componente didáctico de su acto educativo. (Ayala y Loaiza, 2012, p. 129)

Por lo tanto, las prácticas evaluativas desde y con el otro permiten que los estudiantes se apropien de sus procesos formativos y educativos, pero el docente como líder de estos, debe propender por minimizar los errores que se puedan presentar, trascendiendo los currículos, las disciplinas y las experiencias, para que los estudiantes profundicen en el desarrollo de su formación docente.

\section{Reflexiones que se gestan en la relación}

A partir de los apartados anteriores, ubicamos elementos que, más que concluir de manera cerrada, son elementos que permiten generar procesos reflexivos sobre las relaciones comentadas, para tener un proceso de evaluación que contribuya a las habilidades de comprensión, de síntesis, de la inferencia, de la aplicación y de la argumentación, 
lo cual fortalece el proceso formativo generado por la enseñanza (Álvarez, 2003) y que se reflejan en los siguientes puntos de análisis-discusión.

Las prácticas evaluativas desde la formación de profesores y la alteridad deben contribuir a que los procesos de enseñanza y aprendizaje sean compartidos durante todo su desarrollo, valorando el progreso de los aprendizajes a nivel colectivo e individual, por lo cual podríamos hablar de una evaluación democrática (Medina y Salvador, 2005, p. 316), donde se incluyan la realidad cultural (contexto), las distintas corrientes de evaluación, el foco de atención y especialmente que esta no sea excluyente (Chahuán-Jiménez, 2009).

Desde lo expuesto, es posible afirmar que, dependiendo de la perspectiva desde la que se asuma el sujeto-estudiante, se dan diferentes procesos educativos, a saber: (a) asumir el otro como un sujeto instrumental genera procesos educativos técnicos y tradicionales, que desembocan en evaluaciones desde el control y la medición; (b) un estudiante como análogo, da paso a una educación desde el proceso y, por tanto, una evaluación correspondiente al mismo; y (c) cuando el estudiante es entendido desde la apertura, los procesos educativos son analíticos y críticos y el tipo de evaluación que se realiza propende por dar cuenta de ello y generarlo más allá del control y el proceso, generar transformaciones desde su práctica.

A partir de esto, es necesario analizar si la evaluación en clave de alteridad es una opción para configurar el proceso educativo. Se asume dicha ubicación, en cuanto la concreción histórica de la evaluación que debe responder por los "deber ser" de lo educativo, "engendra”, en su lógica implícita, un control e imposición con altas dificultades para no ser tenido en cuenta, por lo que se propone que los procesos evaluativos en la formación de docentes, en diálogos de alteridad, fomenten la justicia, el reconocimiento y la sensibilidad por las diferencias (sociales, económicas y culturales), el fortalecimiento de los principios básicos de las relaciones humanas y del ejercicio profesional docente con responsabilidad (Santos, 2003).

Aquí es posible pensar que una opción está matizada por formar a un maestro que construya un proceso donde los elementos centrales no sean un añadido de la evaluación tradicional, y quizás es necesario pensarlo en términos de la ubicación de otras epistemologías, lógicas y términos para eso de la evaluación; aquí entonces cabe la pregunta: ¿es necesaria la evaluación con su lógica actual? Se menciona así una idea para que entre todos se discuta y construya.

En consonancia con lo anterior, y reconociendo las imposiciones del sistema, donde la formación del maestro se constituye desde modelos de orden cuantitativo-cualitativo sumergidos en la descripción, cuyo espacio para la crítica y proposición son escasos es un obstáculo más en relación de aquello que la evaluación holística quiere, es decir, la pureza del sujeto evaluado como característica a tener en cuenta desde la alteridad, la que puede ser modificada, transformada y agredida con violencia si no se tienen las reflexiones y procesos metodológicos consistentes con lo expuesto. El tipo de evaluación mediada por un proceso conductista en su real esencia no solo dificulta, sino que enrarece y quizás no permite, la alteridad en su corriente más incluyente.

Algunas opciones para desconfigurar-configurar-reconfigurar la evaluación se mediatiza en lo expresado en el texto desde la contextualización y "textualización". Dicha emergencia, en un primer elemento, obviamente, debe estar soportada en la formación del maestro en el sentido de la alteridad, no como opción cognitiva, sino una inmanencia de acción en el acto educativo, pero adicional, se debe pensar en un maestro que conociendo la historia y la epistemología de la evaluación "se atreva" a inventar otras formas de agredir la tradición evaluativa, procesos en los cuales el acercamiento al otro permita la crítica, la duda, la oposición, el acuerdo y la construcción, si se quiere de la evaluación o de lo que simplemente se le puede llamar el seguimiento democrático de lo educativo. ${ }^{8}$

En consonancia con el seguimiento democrático de lo educativo, asumimos que una posibilidad puede ser diseñada cuando se considere la evaluación no como suceso de último momento; en unas

8 En próximas reflexiones, los autores asumen la posibilidad de expresar sus consideraciones de aquello que denominan el seguimiento democrático de lo educativo, en cuanto la historia de lo evaluativo en algunos momentos nos impide salir de la lógica de imposición y control por su esencia misma. 
alternativas podría pensarse en una evaluación desde la experiencia. Allí, las posturas a partir del hacer y el activismo sin sentido deben ser consideradas de otra manera, se habla de una experiencia quizás en las mejores condiciones, real, es decir, la evaluación puede sumergirse en pensarse y desarrollarse en el ethos del maestro, del estudiante, de la comunidad, en general, de la realidad, la evaluación como experiencia es una construcción colectiva matizada por la democracia.

Con estas consideraciones invitamos a los lectores a pensar y ayudar desde su experiencia vital a configurar esa evaluación como apertura al otro en el sentido de lo que se construye y acuerda y no de lo que el sistema y la lógica impositiva positivista determina. Los maestros, las facultades de formación de estos y los interesados en el tema, son invitados a evaluar los actos docentes, para mejorar los actos estudiantiles, de manera cooperativa e incluso individualizada (Santos, 2003), por lo que tenemos un espacio que debatir, construir y ofrecerle a ese sueño de la educación con calidad que aporta a la sociedad.

\section{Referencias}

Ahumada, A. (2001). La evaluación en una concepción de aprendizaje significativo. Santiago de Chile: Ediciones Universitarias Universidad Católica de Valparaíso.

Álvarez, M. (2003). La evaluación educativa en una perspectiva crítica: dilemas prácticos. Revista Opciones Pedagógicas, (28), 49-63.

Ayala, C., Loaiza, Y. (2012). Evaluación de los aprendizajes. El caso de la Licenciatura en Educación Física de la Universidad de Caldas. Manizales: Editorial Universidad de Caldas.

Ayala, C., Souza, N. (2012). Desencuentros académicos en la evaluación como medición y control. Revista Iberoamericana de Estudios en Educación, 7(1), 51-60.

Barbero, J. (2003). La educación desde la comunicación. Bogotá: Editorial Norma.

Bárcena, F. y Mèlich, J. (2000). La educación como acontecimiento ético: natalidad, narración y hospitalidad. Barcelona: Ediciones Paidós Ibérica, S.A.

Blázquez, S. A. (2003). Evaluación en la educación física y el deporte. Barcelona: inde.
Camacho, H. (2003). Pedagogía y didáctica de la educación física. Armenia: Editorial Kinesis.

Cecchini, E. J. (1996). Personalización en la educación física. Tratado de educación personalizada [tomo 19]. Madrid: Rialp.

Cerda, H. (2003). La nueva evaluación educativa, desempeños, logros, competencias y estándares. Bogotá: Editorial Magisterio.

Chahuán-Jiménez, K. (2009). Evaluación cualitativa y gestión del conocimiento. Revista Educación y Educadores, 12(3), 179-195.

Condemarín, M., y Medina, A. (2000). Evaluación de los aprendizajes; un medio para mejorar las competencias lingüísticas y comunicativas. Santiago de Chile: Ministerio de Educación República de Chile.

Díaz, A., Barrón, T., y Díaz, F. (2008). Impacto de la evaluación en la educación superior mexicana. Un estudio en las universidades públicas estatales. México: issue/ anuies/Plaza y Valdés.

Fernández, Julio. (2007). La lucha pedagógica en Colombia. Revista Educación y Cultura. Federación colombiana de educadores, Fecode.

Ferry, G. (1991). El trayecto de la formación. Los enseñantes entre la teoría y la práctica. Barcelona: Ediciones Paidós Ibérica, S.A.

Fichte, J. G. (1977). Discursos a la nación alemana. Madrid: Editorial Nacional.

Freire, P. (1987). Pedagogía del oprimido. Buenos Aires: Siglo XXI.

Gevaert, J. (1984). El problema del hombre. Introducción a la antropología filosófica. Salamanca: Ediciones Sígueme.

Gonzáles, E. (2003). Gestión de la docencia para la sociedad del conocimiento. Políticas públicas, demandas sociales y gestión del conocimiento. Santiago de Chile: Centro Universitario de Desarrollo, cinda.

Guío, G. F. (Julio-diciembre, 2011). Evaluación educativa y de los aprendizajes en educación física: aproximaciones conceptuales. Revista de Investigación Cuerpo, Cultura y Movimiento, 1(2), 57-73.

Gutiérrez, C. (2003). Emmanuel Levinas, lo excepcional como ética. Recuperado de: http://personales.upv.es/ sacuesta/pags/notas_archivos/levinas.pdf

Hernández, C. (2007). Aproximaciones a la discusión sobre el perfil docente. Recuperado el 15/10/2010 de: www.oie.cr 
Hernández, R., y Moreno, S. (2007). La evaluación cualitativa: una práctica compleja. Educación y educadores, 10(2), 215-223.

Honoré, B. (1980). Para una teoría de la formación. Madrid: Nancea, S.A. de Ediciones.

Levinas, E. (1961). Totalidad e infinito. Ensayo sobre la exterioridad. Salamanca: Ediciones Sígueme.

Levinas, E. (1974). Humanismo del otro hombre. México: Siglo XXI.

Levinas, E. (1993). El tiempo y el otro [traducción de José Luís Pardo Torío]. Barcelona: Ediciones Paidós Ibérica S.A.

Maturana, H. (1998). Formación humana y capacitación. Bogotá: Dollmen-TM Editores.

Medina, A., y Salvador, F. (2005). Didáctica general. Madrid: Editorial Pearson Prentice Hall.

Mejía, M., Arias, G., y Pórtela, H. (2007). Módulo de educabilidad (Maestría en Educación). Universidad de Caldas, Manizales.

Meirieu, P., y Develay, M. (2003). Emilio vuelve pronto... ise han vuelto locos! [Traducido por A. Zambrano, $2^{\text {a }}$ ed.]. Santiago de Cali: Editorial Nueva Biblioteca Pedagógica.

Mèlich, J. (1983). Del extraño al cómplice. Barcelona: Editorial Anthropos.

Ministerio de Educación Nacional de Colombia (MEN) (1994). Ley 115, General de Educación. Bogotá.

Ministerio de Educación Nacional de Colombia (MEN) (1997). Decreto 3012 de 1997 y Decreto 3012. Bogotá.

Ministerio de Educación Nacional de Colombia (MEN) (1998). Decreto 3012 de 1997 y Decreto 272. Bogotá.

Ministerio de Educación Nacional de Colombia (MEN) (2003). Decreto 2566 de 2003.

Orrego, J. F. (2009). La Alteridad en la Formación del Licenciado en Educación Física de la Universidad de Caldas (Tesis de Maestría en Educación). Universidad de Caldas, Manizales, Colombia.

Ospina, L. E. (2007). Sobre el objeto de conocimiento de la educación física. Revista Educación y educadores, 10(2), 149-161.

Paukner-Nogués, F., Sanhueza-Henríquez, S., y San Martin-Ramírez, V. (2012). Evaluación de la práctica docente en la Reforma Educacional Chilena. Educación y Educadores, 15(3), 345-362.

Portela, H. (2007). Por una formación que le dé vida a las palabras. En Módulo de educabilidad. Maestría en Educación, I Cohorte. Universidad de Caldas. Manizales, Colombia.

Rentería, P. E. (2004). Formación de docentes. Un reto para las escuelas normales superiores y las facultades de educación. Bogotá: Cooperativa Editorial Magisterio.

Ríos, A. (2004). Contextualización de la evaluación. Manizales: Centro de Publicaciones Universidad de Manizales.

Romero Cerezo, C. (2004). Argumentos sobre la formación inicial de los docentes en Educación Física. Revista de Currículum y Formación de Profesorado, 8(001).

Saavedra, E. (2013). Hacia una evaluación formativa, crítica y artística de la creación literaria. Revista Folios, (37), 167-183.

Sacristán, G., Pérez, Á., (1995). Comprender y transformar la enseñanza [4${ }^{\mathrm{a}} \mathrm{ed}$.]. Madrid: Ediciones Morata, S.L.

Santos, M. Á. (1998). Evaluar es comprender. Buenos Aires: Editorial Magisterio del Río de la Plata.

Santos, M. Á. (1999). Evaluación Educativa 1: Un proceso de diálogo, comprensión y mejora. Buenos Aires: Editorial Magisterio del Río de la Plata.

Santos, M. Á. (2003). Dime cómo evalúas y te diré qué tipo de profesional y de persona eres. Revista Enfoques Educacionales, 5(1), 69-80.

Tamayo, O. (2001). Evolución conceptual desde una perspectiva multidimensional. Aplicación al concepto de respiración (tesis doctoral). Universidad Autónoma de Barcelona.

Vain, P. D. (1998). La evaluación de la docencia universitaria: un problema complejo. El presente trabajo fue elaborado en el marco de la Convocatoria organizada por CONEAU para la realización de trabajos Teórico-Metodológicos sobre evaluación institucional universitaria. Universidad Nacional de Misiones. Buenos Aires. Recuperado el 19/03/2012, de: www. coneau.edu.ar/archivos/1324.pdf

Valencia, C., y Pórtela, H. (2003). Tendencia pedagógica alemana (Maestría en educación docencia). Universidad de Manizales, Manizales.

Vásquez-Rizo, F., y Gabalán-Coello, J. (2012). La evaluación docente en posgrado: variables y factores influyentes. Educación y Educadores, 15(3), 445-460.

Vélez, L. (2013). La educación inclusiva en docentes en formación: su evaluación a partir de la teoría de facetas. Revista Folios, (37), 95-113. 
Universidad Pedagógica Nacional

Facultad de Humanidades

Villada, D. (2002). Evaluación pedagógica. Propuesta incorporada a los procesos educativos. Documento Inédito. Escrito exclusivamente para los docentes del Colegio del Rosario. Manizales.

Villada, D. (2007). Competencias. Manizales: Sintagma Editorial.

Villada, D. (2008). Módulo de evaluación [Maestría en Educación]. Universidad de Caldas, Manizales.

Wulf, C. (1991). Introducción a la ciencia de la educación, entre teoría y práctica. Medellín: Asociación Nacional de Escuelas Normales.

Zambrano Leal, A. (2000). La mirada del sujeto educable. La pedagogía y la cuestión del otro. Santiago de Cali: Editorial Nueva Biblioteca Pedagógica.

Zambrano Leal, A. (2002). El lugar de la didáctica y la pedagogía en la formación de los docentes universitarios: tensiones entre saber disciplinario y pedagógico. Memorias Cátedra Emblemática Álvaro Pío Valencia. Universidad Santiago de Cali.

Zambrano Leal, A. (2005). Didáctica, pedagogía y saber. Bogotá: Cooperativa Editorial Magisterio.

Zuluaga, O. (1989). De Comenio a Herbart. Educación y Cultura (17), 45-51.

Zuluaga, O., Echeverri, A., Martínez, A., Quiceno, H., Sáenz, J., y Álvarez, A. (2005). Pedagogía y epistemología. Bogotá: Editorial Magisterio. 